\title{
Mechanical Studies of Injection Molded Composites with Polypropilene Matrix
}

\author{
Ráthy Istvánné, ${ }^{1}$ Pinke Péter, ${ }^{2}$ Huszák Csenge ${ }^{3}$ \\ Óbuda University, Donát Bánki Faculty of Mechanical and Safety Engineering, Institute of Materials and \\ Manufacturing Sciences, Department of Materials Technology, Budapest, Hungary \\ ${ }^{1}$ rathy.istvanne@bgk.uni-obuda.hu \\ ${ }^{2}$ pinke.peter@bgk.uni-obuda.hu \\ ${ }^{3}$ huszak.csenge@bgk.uni-obuda.hu
}

\begin{abstract}
The wide use of composite materials is mainly due to their excellent strength / mass ratio, corrosion resistance and relatively low price. Approximately $35-40 \%$ of the fibre-reinforced composites are made of thermoplastic polymers in which fibreglass, carbon or natural fibres are most often used as reinforcement, while the remaining $60-65 \%$ is made up of high-tech carbon or glass fibre-reinforced thermosetting composites. Most of them are used in the transport and electronics industries. New processing technologies not only improve the properties of the products but also contribute to reducing costs.

In this paper, we compare the results of mechanical tests with molded standard specimens with polypropylene matrix and test results from cut-outs from injection molded products.
\end{abstract}

Keywords: polypropylene, composites, mechanical properties.

\section{Introduction}

Plastics are now an integral part of our lives, we use them regularly in the home, the workplace, in industry and in agriculture. The production and use of plastics continues to grow all over the world. One of the leading sectors in the plastics and processing industry is injection molding, whose cash flow is estimated to reach USD 252 trillion by 2018 [1]. The widespread use of plastic based composite materials is primarily due to the excellent strength/mass ratio, the corrosion resistance and the relatively low price of composites [2].

\section{Mechanical testing}

In practice, the materials have to support various loads during use. The mechanical properties of the base materials are also tested according to stresses; furthermore we choose the base material to meet the requirements of the component for a particular application. The numerical values of the mechanical properties of a particular structural material are generally found in the literatu- re. However, in many cases too much emphasis is placed on the strength of different types and grades of polymers, and from the point of view of end use, It is not only the mechanical properties that are important. In the practical use of polymers, we can rarely ignore other unfavourable factors affecting a given substance. These include environmental influences and temperature. Temperature significantly affects all the properties of the polymers. As a comparison basis, the characteristics measured at room temperature are usually used. Mechanical properties are strongly influenced by the temperature, depending on the type of polymer. There may be differences between these types of polymer depending on the brand name and the type designation [3]. A question arises concerning different mechanical test results performed on composite specimens from serial production conditions, relating to the results of the standard test specimens. In our article, we have tried to formulate answers to this question. 


\subsection{Tensile testing}

The aim of the tensile test of polymers is to determine the resistance of the material against tensile load, the tensile strength. The course of the test, the shape, the size of the specimen, the acquisition and evaluation of the experimental results are defined in the standard of MSZ EN ISO 527-1: 2012 [4]. The test was carried out on a Zwick Z050 type tensile testing machine. Since the shape of the product did not allow the use of a standard cross-section, the tensile specimens cut from the injection molded $\mathrm{PP}+30 \%$ glass fibre products, were rectangular cross-section $(2 \times 15 \mathrm{~mm})$.

The specimens ruptured with minimal elongation, this was almost a brittle fracture (Figure 1.). Altogether 10 test work pieces were tensile tensed at room temperature.

We define the tensile strength with the following formula:

$$
R_{m}=\frac{F_{\max }}{S_{0}}(\mathrm{MPa})
$$

where $F_{\text {max }}$ is the maximum tensile force $(\mathrm{N}), S_{0}$ is the initial cross section of the test piece $\left(\mathrm{mm}^{2}\right)$.

The measured tensile strength was varied between 63-71 MPa. The tensile curves recorded during the tests are shown in Figure 2.

According to literature data, the $30 \%$ short glass fibre reinforced polypropylene composite has a tensile strength of $82 \mathrm{MPa}$.

The engineering strain values varied $\varepsilon=3,6-$ $4,1 \%$, which were determined by the following relationship:

$$
\varepsilon=\frac{L_{U}-L_{0}}{L_{0}} 100(\%)
$$

where $L_{0}$ is the original gauge length, $L_{u}$ is the final gauge length.

According to literature data, the $30 \%$ short-fiber polypropylene composite strength is $R_{m}=82 \mathrm{MPa}$, the engineering strain value is $\varepsilon=4.9 \%$ [3].

The difference between the measured values and the literature data is derived from the potential differences in the additives between the examined PP matrix and the literature PP matrix.

At the same time, tests were carried out on standard specimens, which were cut out from $\mathrm{PP}+30 \%$ fiberglass composite material. The maximal forces distribution is shown the Figure 3.

In this case the tensile strength varied $R_{m}=79-81$ $\mathrm{MPa}$, the engineering strain value was $\varepsilon=4.83 \%$ These values are very close to the literature data.
The fractured surface was examined with an electron microscope (Figure 4.). The PP base material is visibly adhering to the surface of the glass fibres. The base matrix and the glass fibre together ensures the capacity.

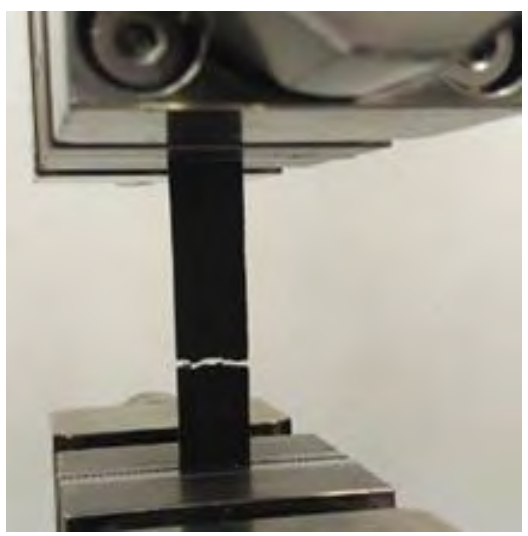

Figure 1. Tensile specimen after fracture

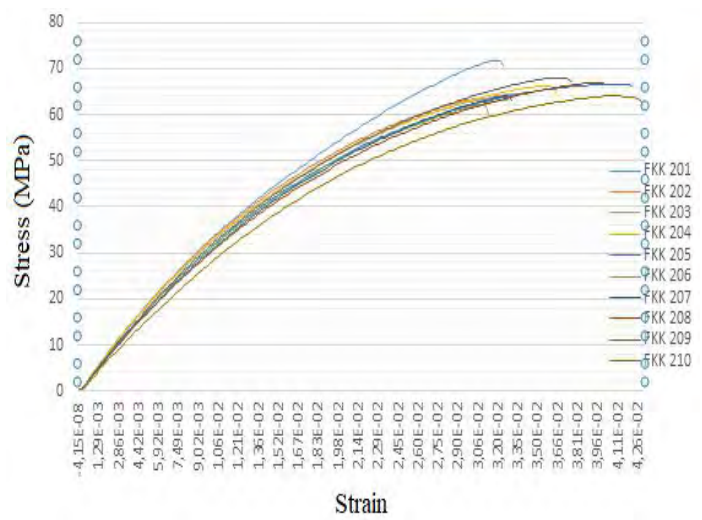

Figure 2. Tensile graphs of the specimens

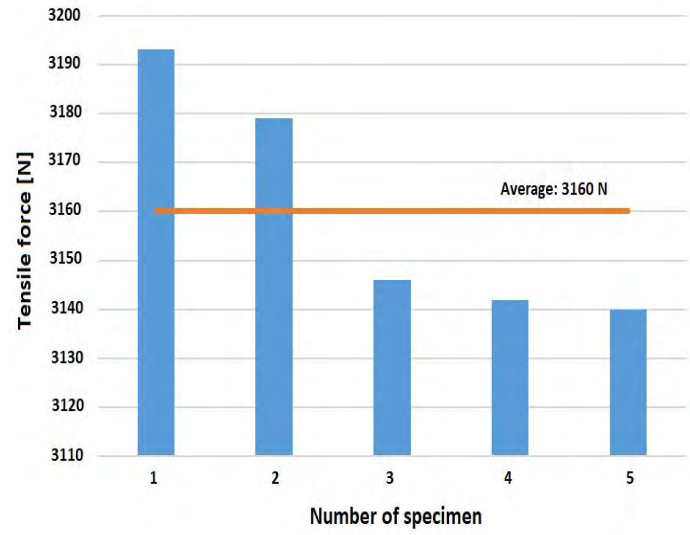

Figure 3. Distribution of maximum forces 


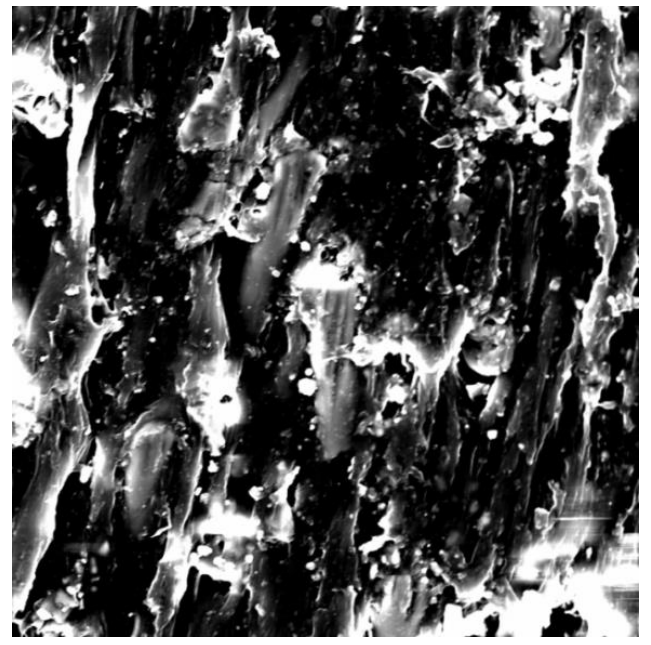

Figure 4. Electron microscopy of the fractured surface

\subsection{Bending test}

Polymers and polymer matrix composites are often characterized by bending tests. The prismatic sample is placed horizontally across two supports and then a force applied to the top of the midpoint. During the test, the load starts from zero and increases steadily until the sample is fractured. Meanwhile, the force $(F)$ and the deflection $(f)$ are measured in the middle of the test. The deformation of the test specimen can be deduced from the deflection and the magnitude of the force [3]. Results are shown in Figure 5.

The following formula was used to determine the bending strength with the maximum bending torque:

$$
R_{m h}=\frac{3 \cdot F_{\max } \cdot L}{2 \cdot B \cdot H^{2}} \quad(M P a)
$$

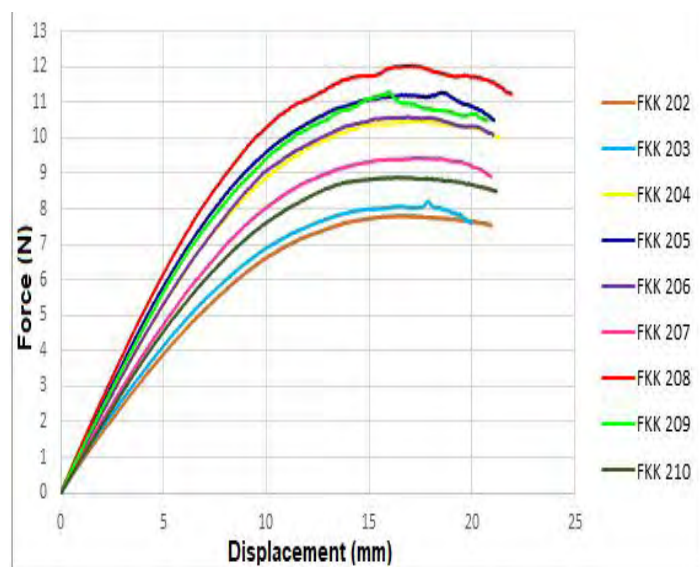

Figure 5. The loading force-bending diagram
The bending modulus of elasticity was calculated using the following formula:

$$
E=\frac{\Delta F L^{3}}{4 \triangle f B H^{3}} \quad(G P a)
$$

The test (Figure 6.) was carried out by an Instron 5965 machine and was performed according to MSZ EN ISO 178:2011. The marking, the sizes, the calculated bending strength and flexural modulus values for the specimens are given in Table 1.

The bending strength of polypropylene without fiberglass was $37 \mathrm{MPa}$, the flexural modulus was $1.4 \mathrm{GPa}$. The polypropylene with $30 \%$ short-fiber specimen cut out of an injection molded product showed a flexural modulus of 52-59 MPa. In the literature a flexural strength of $120 \mathrm{MPa}$, and a flexural modulus of $6 \mathrm{GPa}$ are published for $\mathrm{PP}+30 \% \mathrm{GF}$ (glass fibre) composites.

Table 1. Flexural strength and Young's modulus values determined by the tests

\begin{tabular}{|c|l|l|l|l|l|c|}
\hline Notation & $\begin{array}{c}\text { Fmax } \\
(\mathbf{N})\end{array}$ & $\begin{array}{c}\mathbf{L} \\
(\mathbf{m m})\end{array}$ & $\begin{array}{c}\mathbf{B} \\
(\mathbf{m m})\end{array}$ & $\begin{array}{c}\mathbf{H} \\
(\mathbf{m m})\end{array}$ & $\begin{array}{c}\mathbf{\sigma} \\
(\mathbf{M P a})\end{array}$ & $\begin{array}{c}\mathbf{R} \\
(\mathbf{M P a})\end{array}$ \\
\hline FKK 202 & 7.8 & 70 & 7.61 & 1.43 & 52.6 & 1799.1 \\
\hline FKK 203 & 8.2 & 70 & 7.69 & 1.44 & 54.0 & 1714.3 \\
\hline FKK 204 & 8.9 & 70 & 7.91 & 1.50 & 52.5 & 1665.0 \\
\hline FKK 205 & 11.3 & 70 & 8.25 & 1.56 & 59.1 & 1674.2 \\
\hline FKK 206 & 10.6 & 70 & 8.30 & 1.53 & 57.3 & 1815.2 \\
\hline FKK 207 & 9.4 & 70 & 8.06 & 1.51 & 53.7 & 1662.7 \\
\hline FKK 208 & 12 & 70 & 8.34 & 1.59 & 59.8 & 1798.2 \\
\hline FKK 209 & 11.3 & 70 & 8.29 & 1.55 & 59.6 & 1965.4 \\
\hline FKK 210 & 10.5 & 70 & 8.21 & 1.53 & 57.4 & 1848.7 \\
\hline Átlag & & & & & 56.2 & 1771.4 \\
\hline
\end{tabular}

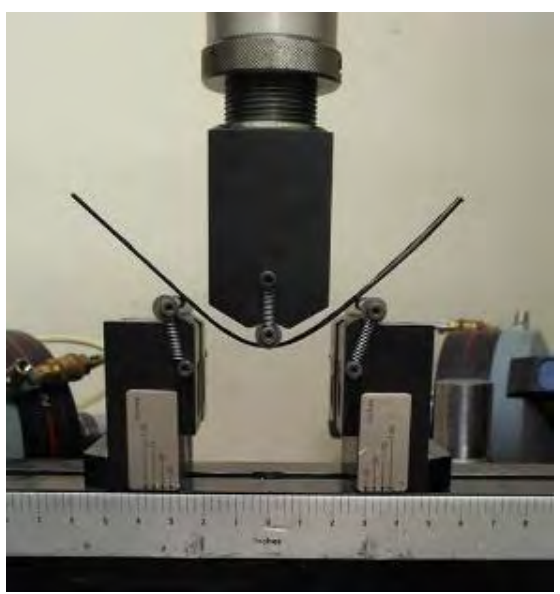

Figure 6. The sample in bending test 
The average of the bending strength values is shown in Figure 7.

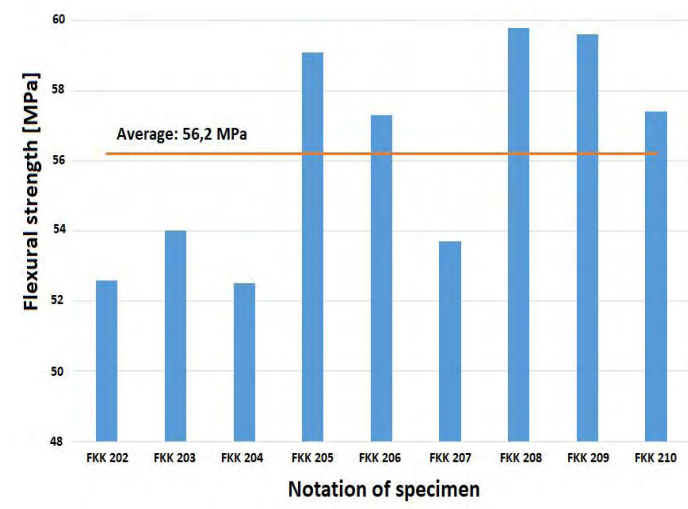

Figure 7. The bending strength values

\subsection{Impact test}

Methods for Dynamic Material testing provide a solution for the determination of loads that cause fracture, and the toughness of the particular structural material. In the case of polymers, toughness relates to their energy absorbing ability. For structural materials, it can be stated that the material with higher impact energy has a higher toughness. The test may be carried out with notched and non-notched specimens [4]. The specimens we used were non-notched. We employed a Charpy Impact Testing Machine according to MSZ EN ISO 179-1:2010. The dimensions of the specimens are shown in Table 2.

AThe Charpy impact toughness measured on the polypropylene based $30 \%$ glass fiber reinforced composite with a non-notched specimen was $4 \mathrm{~J} / \mathrm{cm}^{2}$ [5], this is equal to $40 \mathrm{~kJ} / \mathrm{m}^{2}$.

Table 2. Impact test sample sizes

\begin{tabular}{|c|c|c|c|}
\hline $\begin{array}{c}\text { Sign of } \\
\text { work-piece }\end{array}$ & $\begin{array}{l}\text { Width } \\
\text { (mm) }\end{array}$ & $\begin{array}{l}\text { Thickness } \\
\text { (mm) }\end{array}$ & $\underset{\left(\mathbf{m m}^{2}\right)}{\mathbf{A}}$ \\
\hline FKK 202 & 3.89 & 3.81 & 14.8209 \\
\hline FKK 203 & 3.95 & 3.71 & 14.6545 \\
\hline FKK 204 & 3.85 & 3.79 & 14.5915 \\
\hline FKK 205 & 3.82 & 3.79 & 14.4778 \\
\hline FKK 206 & 3.84 & 3.86 & 14.8224 \\
\hline FKK 207 & 3.81 & 3.76 & 14.3256 \\
\hline FKK 208 & 3.71 & 3.86 & 14,3206 \\
\hline FKK 209 & 3.84 & 3.81 & 14.6304 \\
\hline FKK 210 & 3.70 & 3.85 & 14.2450 \\
\hline
\end{tabular}

The values we measured and calculated are shown in Table 3. The impact toughness values are between $27-36 \mathrm{KJ} / \mathrm{m}^{2}$.

The average is shown in Figure 8.

These results compare well with the literature data.

Table 3. Impact test and impact strength value

\begin{tabular}{|c|c|c|}
\hline $\begin{array}{c}\text { Sign of } \\
\text { work-piece }\end{array}$ & $\begin{array}{c}\text { Absorbed energy } \\
\text { (J) }\end{array}$ & $\begin{array}{c}\text { Impact strength } \\
\left(\mathbf{k J} / \mathbf{m}^{\mathbf{2}}\right)\end{array}$ \\
\hline FKK 202 & 0.46 & 31 \\
\hline FKK 203 & 0.41 & 28 \\
\hline FKK 204 & 0.40 & 27 \\
\hline FKK 205 & 0.52 & 35 \\
\hline FKK 206 & 0.52 & 35 \\
\hline FKK 207 & 0.48 & 33 \\
\hline FKK 208 & 0.47 & 32 \\
\hline FKK 209 & 0.53 & 36 \\
\hline FKK 210 & 0.45 & 32 \\
\hline
\end{tabular}

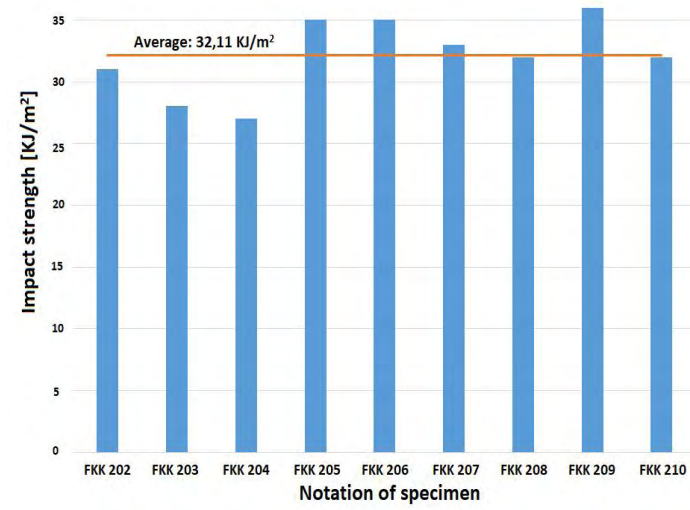

Figure 8. The average of the impact strength values

\section{Conclusion}

Mechanical tests were performed with specimens cut from workpieces produced in series production in industrial conditions. We find that the magnitudes of the tensile test results are consistent with the results of experiments with standard test specimens, but they show lesser values. This may be the effect of additives not known to us in these industrial products.

Bending tests showed greater differences between the measured and the literature data, this can be explained by the difference in PP matrix additives. The impact test results are well-aligned with the literature data. 


\section{References}

[1] Transparency Market Research: Injection Molded Plastics Market - Global Industry Analysis, Size, Share, Growth and Forecast, 2010-2018.

https://pitchengine.com/pitches/8f64cc4f-8df44314-9eeb-5e9c534da54d (accessed 1.03.2017)

[2] Kar K. K. (ed.): Composite Materials: Processing, Applications, Characterizations. Springer Verlag, Berlin-Heidelberg, 2017.

https://doi.org/10.1007/978-3-662-49514-8
[3] Szakács H., Varga Cs., Nagy R.: Polimerek méréstechnikája. Pannon University, Veszprém, 2012. 71-76.

[4] Varga Cs.: Müszaki müanyagok. part 2. Pannon University, Veszprém, 2012. 24.

[5] Czél Gy., Kollár, M.: Anyagvizsgálati praktikum. Sunplant Kft., 2009. 36. 